RIGINAL PAPER

M. Grasby · C. D. Frith · E. Paulesu - K. J. Friston

S. J. Frackowiak · R. J. Dolan

\title{
he effect of the muscarinic antagonist scopolamine regional cerebral blood flow during the performance of a memory task
}

bstract Scopolamine, a muscarinic antagonist, impairs emory performance in both humans and animals. In this ady, repeated measurements of regional cerebral blood ow ( $\mathrm{rCBF}$ ) were made in normal volunteers whilst perming auditory verbal memory tasks, before and after e administration of scopolamine $(0.4 \mathrm{mg}$ s.c.) or placeCompared to placebo, scopolamine increased blood ow in the lateral occipital cortex bilaterally and the left bitofrontal region. Scopolamine decreased $\mathrm{rCBF}$ in the gion of the right thalamus, the precuneus and the right ad left lateral premotor areas. Scopolamine attenuated emory-task-induced increases of rCBF in the left and ght prefrontal cortex and the right anterior cingulate reion. These data suggest that acute blockade of cholineric neurotransmission affects diverse brain areas, includg components of the visual and motor systems, and, in dition, modulates memory task activations at distinct ints in a distributed network for memory function.

ley words Scopolamine - Memory Positron emission mography $\cdot$ Human

M. Grasby ( ) C. D. Frith · E. Paulesu - K. J. Friston

IS. J. Frackowiak · R. J. Dolan

IRC Cyclotron Unit, Hammersmith Hospital, Du Cane Road, ondon W12 OHS, UK; Tel: +81-44-740-3162-3705, ax no: $+81-44-743-3987$

kpartment of Psychology, University College, London, ICIH OAT, UK

M. Grasby · K. J. Friston · R. S. J. Frackowiak · R. J. Dolan tational Hospital for Neurology and Neurosurgery,

ondon WC1N 3BG, UK

B-CNR, Instituto Scientifico H San Raffaele, Milan, Italy

\section{Introduction}

Scopolamine (hyoscine hydrobromide) is a muscarinic antagonist with central and peripheral actions (Ketchum et al. 1973; Heller-Brown 1990). It has been extensively investigated for its effects on higher cognitive processes particularly memory and attention (see Collerton 1987; Kopelman 1987 for reviews). In summary, scopolamine impairs performance on memory tasks that exceed the limited capacity of primary memory (Kopelman 1987). Thus while digit, word and block span is unaffected, scopolamine impairs the performance on supraspan tasks such as the recall of series of nine digits (Drachman and Leavitt 1974) or the free recall of a supraspan word list (Crow and Grove-White 1973). In keeping with effects on secondary memory, scopolamine impairs performance at the beginning and in the mid-portion of the serial position curve but the recency effect is unimpaired (Crow and Grove-White 1973). Despite these findings, it remains a matter of continuing debate whether attentional and or memory mechanisms are primarily impaired by scopolamine (Kopelman 1987; Sahakian 1988).

A clearer understanding of scopolamine's effect in the CNS might be obtained by determining which brain areas are targeted, functionally, by scopolamine administration in humans. Positron emission tomography (PET) can be used to measure drug-induced changes in regional cerebral blood flow (rCBF) or glucose utilization which, under most circumstances, are valid indices of neuronal activity in vivo (McCulloch 1982; Soncrant et al. 1986; Raichle 1987; Posner et al. 1988). In addition, when a pharmacological manipulation is combined with a psychological challenge, sites of functional interaction between a drug and the rCBF change induced by a psychological task can be determined (Friston et al. 1992; Grasby et al. 1992). Using PET, we report the effects on rCBF of a single subcutaneous dose of scopolamine $(0.4 \mathrm{mg})$ in normal volunteers whilst subjects performed subspan and supraspan auditory-verbal memory tasks. A supraspan-subspan memory activation paradigm was chosen, as scopolamine impairs supraspan word list re- 
call (see above) and because the pattern of rCBF activations with this paradigm has been characterized previously (Grasby et al. 1993). Specifically, our aims were to determine (1) the brain areas altered by scopolamine administration, as indexed by changes in rCBF, and (2) the brain sites of interaction between scopolamine and the rCBF activations induced by a supraspan memory task.

\section{Materials and methods}

Subjects

Twelve right-handed male volunteers (age range 21-36 years) took part in the study, which was approved by the local hospital ethics committee and the Advisory Committee on the Administration of Radioactive Substances (ARSAC), UK.

\section{Drug administration}

Each subject underwent six PET measurements of rCBF over a $90 \mathrm{~min}$ period. Two measurements of $\mathrm{rCBF}$ were undertaken before $(t=-12$ and $-2 \mathrm{~min}$ ), and four measurements after subcutaneous scopolamine $(0.4 \mathrm{mg})$ or placebo $(0.5 \mathrm{ml}$ saline for injection) $(t=+15,+25,+55,+65 \mathrm{~min}$ for scopolamine; $t=+20,+30,+50$, +60 min for placebo). Scan times post scopolamine were chosen on the basis of scopolamine kinetics and the time course of impairment of memory function. Scopolamine is rapidly absorbed following subcutaneous injection and impairment of memory function is usually seen within 30 to $60 \mathrm{~min}$. The 5 -min difference in post-drug scan times between the placebo and scopolamine conditions was because the placebo group was used as a data base for comparison with other drug-memory interaction studies with slightly different scanning times (see Grasby et al. 1992). Subjects were blind to the drug administered. Six subjects received scopolamine and six received placebo.

\section{Experimental design}

The design of this experiment is illustrated in Fig. 1. Subjects performed memory tasks during PET scanning. The tasks used were a subspan memory task ( $\mathrm{M}-$-) performed during the first, third and fifth scans and a supraspan task (M+) during the second, fourth and sixth scans. In the subspan task, subjects were asked to remember and immediately verbally recall a series of five-word lists presented auditorily. Nine different five-word lists were presented over the 2 min of the PET scan. In the supraspan task, subjects were required to remember and immediately verbally recall a 15 word list presented auditorily. The 15-word list was presented three times during the PET scan, thus the number of words heard in both tasks was 45 in total $(5 \times 9,15 \times 3)$. The essential difference between the subspan and supraspan tasks was taken to be the greater engagement of long-term memory processes in the supraspan condition (see Grasby et al. 1993). Words were presented at the rate of one every $2 \mathrm{~s}$. Different 15 -word lists were used for each PET scan. Words were high frequency, concrete, imageable and were taken from the Oxford Psycholinguistic Data Base (Quinlan 1992). Scopolamine or placebo was given after the second scan. The subjects eyes were closed throughout scanning. The total number of words correctly recalled from each subspan and supraspan task was noted.

\section{PET scanning}

Scans were obtained using a CTI model 931-08/12 PET scanner (CTI, Knoxville, Tenn., USA) (Spinks et al. 1988). Scans were reconstructed using a Hanning filter with a cut-off frequency of 0.5
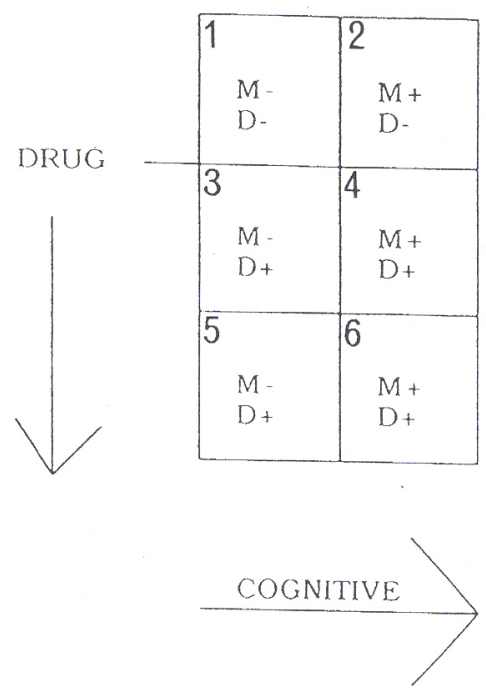

Fig. 1 Experimental design. Each box represents a PET scan fron 1 to 6 ( $M$ - subspan memory task, $M+$ supraspan memory task, $D$ no drug, $D+$ scopolamine or placebo) The main effect of the drus: is given by the comparison [scans $3+4+5+6$ minus scans $1+2$ ]. Thi main effect of the memory (supraspan) activation task is given br: the comparison $[\operatorname{scan}(2-1)+(4-3)+(6-5)]$. The interaction e fect of drug with memory activation is given by the compariso [scan 2-1] compared to [scan (4-3)+(6-5)]

giving a transaxial resolution of $8.5 \mathrm{~mm}$ full width at half max mum (FWHM) and an axial resolution of $6.75 \mathrm{~mm}$ for each of t. transverse planes, with a resulting total field of view of $10.13 \mathrm{at}$ in this direction. To index rCBF, subjects inhaled trace amounts ${ }^{15} \mathrm{CO}_{2}$, mixed with air, at a concentration of $6 \mathrm{MBq} / \mathrm{ml}$ and a flor rate of $500 \mathrm{ml} / \mathrm{min}$ through a disposable oxygen face mask for period of $2 \mathrm{~min}$. Two PET scans were collected over a period $2.5 \mathrm{~min}$ beginning $0.5 \mathrm{~min}$ before the inhalation of ${ }^{15} \mathrm{CO}_{2}$ (bari ground scan duration $0.5 \mathrm{~min}$, second scan duration $2 \mathrm{~min}$ ) (adar ed from Lammertsma et al. 1990). In this study, the integrate counts per pixel for the 2-min build-up phase of radioactivity the brain during ${ }^{15} \mathrm{CO}_{2}$ inhalation were used as an index of ${ }^{6} 8$ (Mazziota et al. 1985; Fox and Mintun 1989).

Measurement of side effects of scopolamine administration

Subjective stress and arousal were assessed on three occas $(t=-15 \mathrm{~min}$ pre-scopolamine/placebo and $t=+30 \mathrm{~min},+60 \mathrm{mi}$ post-scopolamine/placebo) using a 24 -item questionnaire (Mabo et al. 1978). In addition, subjects rated the symptom of dry mate on a visual analogue scale $(0="$ not at all", $100="$ a great deal").

\section{Data analysis}

Each reconstructed $\mathrm{rCBF}$ scan consisting of 15 primary transy planes was interpolated to 43 planes to render the voxels appre mately cubic. For each subject, head movement between s was corrected by aligning all scans using automated image rot tration (AIR) software specfically developed for this pury (Woods et al. 1992). Images were then transformed into a stantio stereotactic space (Friston et al. 1989, 1991a). Such transform tion of the data allows for pixel by pixel averaging of data act subjects. In the standard space, one voxel represents $2 \times 2 \times 4 \mathrm{mt}$ the $x, y$ and $z$ dimensions, respectively, allowing direct crossetit ence to the anatomical features in a standard stereotactic atlas 1 lairach and Tournoux 1988). A gaussian filter $(20 \mathrm{~mm}$ FWh was applied to smooth each image to account for inter-subjerd ferences in gyral and functional anatomy and to suppress hight. quency noise in the images. 
Differences in global activity within and between subjects removed by analysis of covariance (Wildt and Ahtola 1978) pixel by pixel basis with global counts as covariate and real activity across subjects for each task as treatment. This proire was undertaken as inter- and intra-subject differences in al $\mathrm{CBF}$ reduce the likelihood of detecting alterations in $\mathrm{rCBF}$ wing physiological stimulation (Friston et al. 1990). It should noted that scopolamine and memory-induced changes in $\mathrm{rCBF}$ resent relative increases or decreases of $\mathrm{rCBF}$ following the malization of global radioactive counts to a flow value of $\mathrm{m} / \mathrm{dl} / \mathrm{min}$.

For each pixel, in stereotactic space, the analysis of covariance NCOVA) generated six condition-specific (i.e., scans 1-6), an $\mathrm{rCBF}$ equivalent values (normalized to $50 \mathrm{ml} / \mathrm{dl} / \mathrm{min}$ ) and an ociated error variance. This error variance was computed indeadently for the placebo and scopolamine groups using a comely randomized block design ANCOVA. The ANCOVA procee assumes that the magnitude of $\mathrm{rCBF}$ change following task tivation is additive rather than proportional to global flow. The erimental validity of the additive model has been shown by ston et al. (1990) and Ramsay et al. (1993). Another assumpis that of no systematic change in the global covariate (global oactivity counts) across conditions. This assumption was testand confirmed by analysis of variance (ANOVA) on the global dioactivity counts $(F=1.04$, df $5,30, P>0.05)$.

\section{distical comparisons}

changes of interest were:

The main effect of scopolamine compared to placebo ( $\mathrm{rCBF}$ nges due to scopolamine compared to placebo under both suband supraspan conditions).

The main effect of the memory task ( $\mathrm{rCBF}$ increases due to the raspan task compared to the subspan memory task). This effect determined using the group of subjects given placebo.

The interaction effect of scopolamine on the memory task, that copolamine-induced rCBF attenuations or augmentations of suspan task rCBF increases. This represents the interaction: mory-induced rCBF activations (supraspan - subspan), pre-scomine versus post-scopolamine. To control for any non-specific enuations or augmentations of supraspan $\mathrm{rCBF}$ activations, due ime or placebo effects, the placebo group was similarly examd. Qualitative comparisons between the attenuations and augntations in the two groups were then made. To do this the same set of pixels (identified on the basis of supraspan rCBF inases in the scopolamine group) was examined in the placebo up to identify possible time/placebo interaction effects.

The above effects were computed on a pixel by pixel basis usthe $t$ statistic with the appropriate linear contrasts (Hand and lor 1991) and adjusted error variance. The resulting sets of $t$ ues constitute statistical parametric maps $[\operatorname{SPM}(t)]$ (Friston et 1991b). With so many comparisons being made, many $t$ values ch conventional levels of significance by chance. Therefore a ct threshold of $P<0.001$ per pixel was used to define the profile copolamine-induced rCBF changes compared to placebo. This shold has been found to protect against false positives (Bailey 1. 1991). For the memory task comparison the same threshold also used.

Pixels significantly activated in the supraspan-subspan comparin the scopolamine group at $P<0.001$ were further analyzed en computing the attenuating and augmenting effect of scopol- amine or placebo in these pixels. The threshold for the attenuating or augmeriting effects of scopolamine or placebo on memory activation was set at $P<0.05$. Thus, the final probability of a main effect of memory activation and a drug-induced attenuation (augmentation) of memory activation, occurring in the same pixel, is the product of the probabilities $P<0.001 \times P<0.05(P<0.00005)$.

Image analysis was performed using SPM software (MRC Cyclotron Unit, London, UK) on a SPARC 1 workstation (Sun Microsystems, Surrey, UK) using an interactive image analysis software package ANALYZE (Biodynamic Research Unit, Mayo Clinic, USA; Robb 1990). Calculations and image matrix manipulations were performed in PRO MATLAB (Mathworks, New York, USA).

\section{Results}

\section{Memory performance}

Scopolamine had no effect on the number of words correctly recalled in the five-word list task; a high level of performance was recorded throughout the study (97\% or above correct recall for all scans). A two-way ANOVA, drug (2) ×supraspan task (3) showed a significant effect of drug on supraspan task $(F=3.568$, df $2, P<0.05$; Table $1)$. Scopolamine reduced the numbers of words correctly recalled in the 15-word list task compared to placebo, an effect most apparent in the second post-drug supraspan trial, in which recall on the first, second and third presentation of a 15-word list was impaired.

\section{Sites of scopolamine-induced increases} of rCBF compared to placebo

Three foci of increased rCBF were observed. Two foci were located in the left and right lateral occipital cortex and one in the left inferior frontal region (Table 2, Fig. 2).

Sites of scopolamine-induced decreases of rCBF compared to placebo

Decreases of $\mathrm{rCBF}$ were noted in the region of the right thalamus, the precuneus and the right and left premotor areas (Table 2, Fig. 3).

\section{Sites of memory (supraspan)-induced increases of $\mathrm{rCBF}$ in the placebo-treated group}

Memory (supraspan-subspan) induced increases of rCBF were noted in the left and right prefrontal cortex, the pre-

1 Effect of scopolamine on memory performance. The values represent the number of words in the list correctly recalled ean $\pm \mathrm{SD}$ ). ( $P$ Placebo, $S$ scopolamine, $1 s t, 2 n d, 3 r d$ presentations of a single 15 -word list)

\begin{tabular}{|c|c|c|c|c|c|c|c|c|}
\hline \multicolumn{3}{|c|}{ Pre-drug (scan 2) } & \multicolumn{3}{|c|}{ Post-drug (scan 4) } & \multicolumn{3}{|c|}{ Post-drug (scan 6) } \\
\hline $1 \mathrm{st}$ & 2nd & $3 \mathrm{rd}$ & $1 \mathrm{st}$ & 2nd & $3 \mathrm{rd}$ & $1 \mathrm{st}$ & 2nd & $3 \mathrm{rd}$ \\
\hline $\begin{array}{l}7.0 \pm 2.6 \\
7.7 \pm 2.2\end{array}$ & $\begin{array}{r}9.5 \pm 1.5 \\
10.0 \pm 2.0\end{array}$ & $\begin{array}{l}10.7 \pm 1.5 \\
11.5 \pm 2.1\end{array}$ & $\begin{array}{l}7.5 \pm 2.4 \\
6.33 \pm 1.5\end{array}$ & $\begin{array}{l}11.2 \pm 2.5 \\
10.5 \pm 2.4\end{array}$ & $\begin{array}{l}12.7 \pm 2.7 \\
11.67 \pm 2.3\end{array}$ & $\begin{array}{l}8.5 \pm 1.8 \\
6.33 \pm 3.1\end{array}$ & $\begin{array}{r}10.8 \pm 2.0 \\
8.5 \pm 2.6\end{array}$ & $\begin{array}{c}11.7 \pm 1.9 \\
9.83 \pm 1.6\end{array}$ \\
\hline
\end{tabular}


Table 2 Co-ordinates of maximal significant change in rCBF: scopolamine compared to placebo. Co-ordinates of the $x, y$ and $z$ planes are in millimetres, from the atlas of Talairach and Tournoux (1988). $Z>3.09=P<0.001$. ( $L$ Left, $R$ right)

\begin{tabular}{lrrrr}
\hline Brain region & \multicolumn{2}{l}{ Co-ordinate } & \multirow{2}{*}{ Z value } \\
\cline { 2 - 3 } & $x$ & $y$ & $z$ & \\
\hline Increased rCBF & & & & \\
L lateral occipital cortex & -32 & -78 & +0 & 3.63 \\
R lateral occipital cortex & +26 & -88 & -8 & 3.46 \\
& +20 & -80 & +12 & 3.80 \\
L inferior frontal region & -22 & +28 & -4 & 3.36 \\
Decreased rCBF & & & & \\
R thalamus & +10 & -20 & +4 & 3.13 \\
& +18 & -18 & +12 & 3.59 \\
Precuneus & -14 & -42 & +32 & 3.23 \\
R premotor area & +22 & +2 & +44 & 3.28 \\
L premotor area & +14 & -10 & +52 & 4.22 \\
& -24 & +6 & +52 & 3.71 \\
\hline
\end{tabular}

Fig. 2A-C Scopolamine-induced increases of rCBF. A Tranverse images in the stereotactic space of Talairach and Tournoux (1988) showing areas of significant increase in $\mathrm{rCBF}$ with scopolamine. Numbers refer to millimetres above or below the anterior-posterior commissure line. The coloured square at the bottom left of an image represents a significance of $P<0.001$ for scopolamine-induced increases of $\mathrm{rCBF}$, compared to placebo. $\mathbf{B}$ The spatial distribution of significant pixels at $P<0.001$ for scopolamine -induced increases of $\mathrm{rCBF}$, compared to placebo. Images are shown as integrated projections through sagittal $(a)$, coronal $(b)$ and tranverse $(c)$ views of the brain ( $R$ right). C For illustrative purposes only, significant pixels at $P<0.001$ have been rendered onto lateral views of the left and right hemisphere taken from the Talairach and Tournoux atlas cuneus region, anterior cingulate and the right and lef premotor areas (Table 3, Fig. 4); a similar set of area were activated with the supraspan task in the scopol amine group (see Figs. 5, 6).

Sites of scopolamine- and/or placebo-induced attenuation of supraspan increases of $\mathrm{rCBF}$

Scopolamine attenuated supraspan-induced $\mathrm{rCBF}$ in creases at four locations. These attenuations were local ized to the left prefrontal cortex (predominantly the middle frontal gyrus), the right prefrontal cortex (middle and superior frontal gyri), a region bordering the right anterior cingulate and adjacent right prefrontal cortex (pre dominantly middle frontal gyrus), and the left inferior lateral parietal region (predominantly BA 39/40) (Table 3 , Figs. 5,7 ). Comparison of the attenuation foci showed that of the four locations identified above, the placebo condition only attenuated supraspan activations in the left inferior parietal region (Fig. 5). Placebo was also as sociated with attenuation of supraspan $\mathrm{rCBF}$ increases it the superior aspect of the left prefrontal region, but this area was not congruent with the attenuations seen in the scopolamine group (see Fig. 5).

Sites of scopolamine- and/or placebo-induced augmentation of supraspan increases of rCBF

Scopolamine augmented supraspan-induced $\mathrm{rCBF}$ in creases in the region of the right precuneus (Table 3

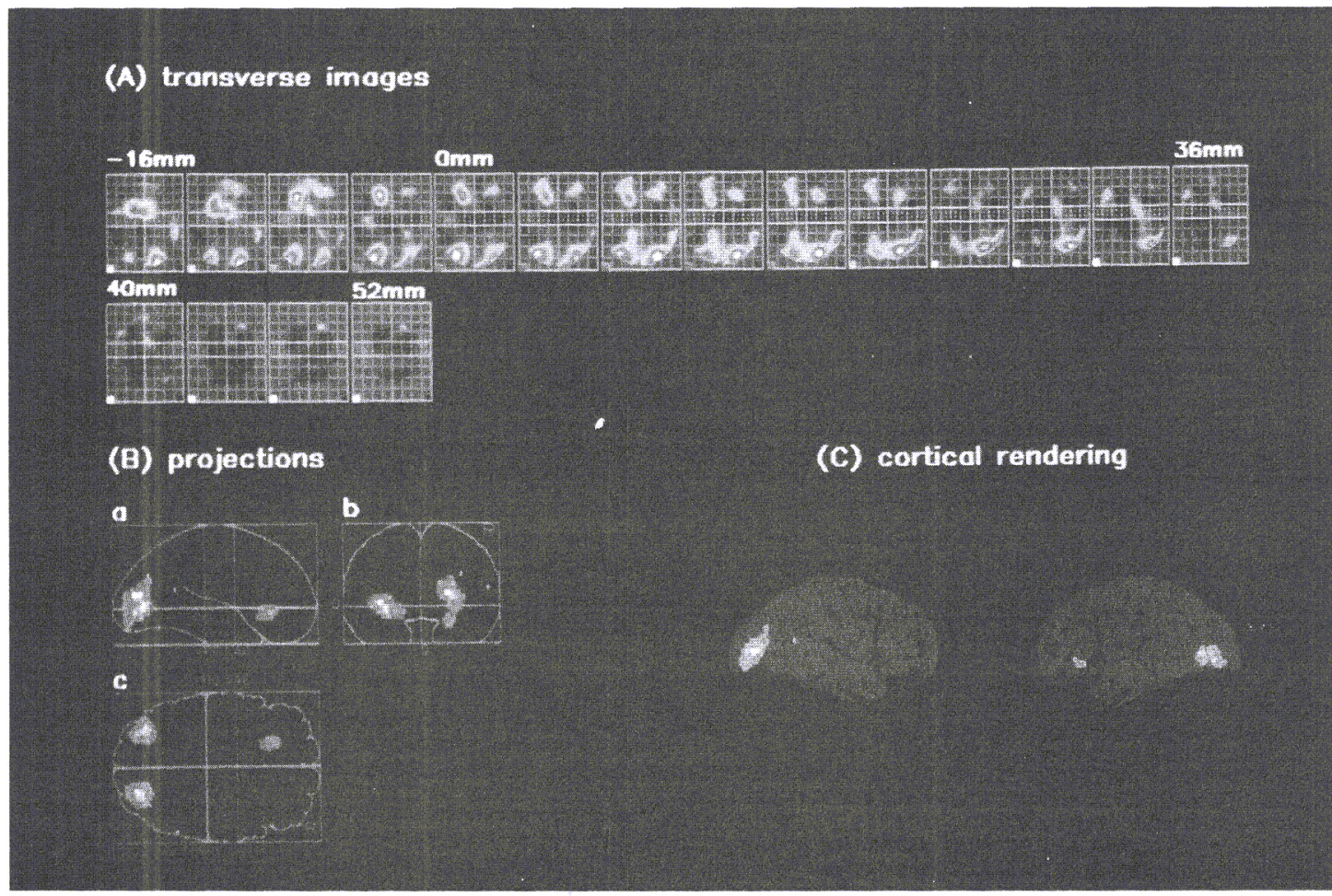




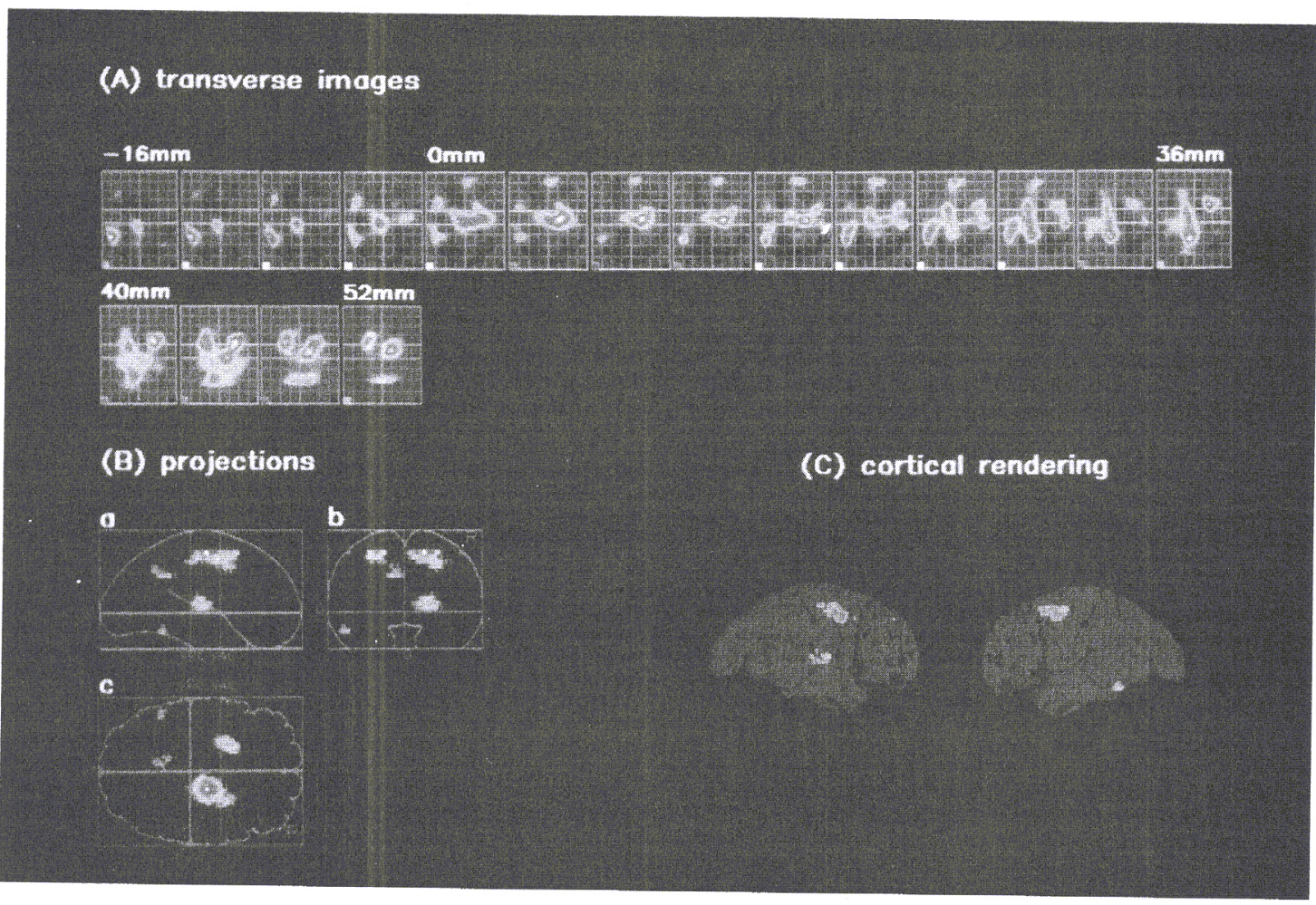

3A-C Scopolamine-induced decreases of rCBF. A Tranverse ss in the stereotactic space of Talairach and Tournoux (1988) ing areas of significant decrease of $\mathrm{rCBF}$ with scopolamine. vers refer to millimetres above or below the anterior-posterior issure line. The coloured square at the bottom left of an imspresents a significance of $P<0.001$ for scopolamine -induced ases of rCBF, compared to placebo. $\mathbf{B}$ The spatial distribuif significant pixels at $P<0.001$ for scopolamine -induced deis of $\mathrm{rCBF}$, compared to placebo. Images are shown as inte1 projections through sagittal $(a)$, coronal $(b)$ and tranverse ews of the brain ( $R$ right). C For illustrative purposes only, icant pixels at $P<0.001$ have been rendered onto lateral of the left and right hemisphere taken from the Talairach ournoux atlas

6). A similar focus of augmentation was seen in the bo condition in the region of the precuneus. Placeugmentations (in some cases extending over a few verse planes only), were also noted in the right preal cortex, right anterior cingulate region and the and left lateral parietal regions (Fig. 6).

$s$, arousal and side effects

opolamine administration

zct-rated levels of stress and arousal decreased durle time course of the PET study in both the scopole- and placebo-treated groups - stress: placebo to $14 \pm 2$, scopolamine $22 \pm 10$ to $17 \pm 9$; arousal: pla$-1 \pm 2$ to $-7 \pm 3$, scopolamine $4 \pm 4$ to $-6 \pm 4$ (mean \pm SD). le visual analogue scale, all the subjects treated with lamine reported an increase in rating of dry mouth scopolamine median $s c o r e=15$, post-scopolamine an score $=70$ ).
Table 3 Co-ordinates for memory-induced rCBF increases, attenuation and augmentation with scopolamine. Co-ordinates of $x, y$ and $z$ planes are in millimetres, from the atlas of Talairach and Tournoux (1988). $Z>3.09=P<0.001, Z>1.65=P<0.05$. (ant. Anterior, inf interior, $L$ left, Lat. lateral, $R$ right)

\begin{tabular}{llll}
\hline Brain region & \multicolumn{2}{l}{ Co-ordinate } & Z value \\
\cline { 2 - 4 } & $x$ & $y$ & $z$
\end{tabular}

Supraspan activations in placebo group

$\begin{array}{lllll}\mathrm{L} \text { prefrontal cortex } & -22 & +52 & +0 & 3.8\end{array}$

$\begin{array}{llll}-36 & +18 & +28 & 4.9\end{array}$

$\begin{array}{lllll}R \text { prefrontal cortex } & +28 & +54 & -4 & 4.4\end{array}$

$\begin{array}{llll}+32 & +42 & +20 & 4.5\end{array}$

$\begin{array}{lllll}\text { Ant. cingulate } & +8 & +18 & +20 & 4.1\end{array}$

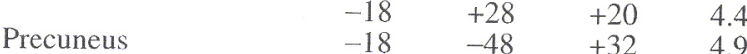

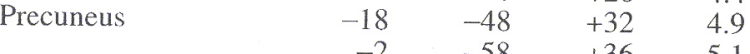

$\begin{array}{rrrr}-2 & -58 & +36 & 5.1 \\ -16 & -46 & +36 & 4.9\end{array}$

$\begin{array}{lllll}\text { Lat. premotor areas } & +14 & -60 & +40 & 6.4 \\ & -24 & +12 & +48 & 6.4\end{array}$

$\begin{array}{llll}-24 & +12 & +48 & 6.4 \\ +20 & +48 & 5.3\end{array}$

Attenuation with scopolamine of supraspan activations $\begin{array}{lllll}R \text { ant cingulate/ } & +20 & +30 & +16 & 2.48\end{array}$

$R$ prefrontal cortex region

$\begin{array}{lllll}R \text { prefrontal cortex } & +20 & +18 & +40 & 3.07\end{array}$

$\begin{array}{lllll}\mathrm{L} \text { prefrontal cortex } & -38 & +42 & +4 & 3.02\end{array}$

$\begin{array}{lllll}\mathrm{L} \text { inf parietal area* } & -38 & +24 & +28 & 2.01\end{array}$

$\begin{array}{llll}-40 & -46 & +44 & 2.78\end{array}$

(Placebo) $\quad(-38) \quad(-70) \quad(+28)$

Augmentation with scopolamine of supraspan activations
Precuneus*
$+16 \quad-72 \quad+44$
2.49

$\begin{array}{lllll}\text { (Placebo) } & (+0) & (-60) & (+48) & (2.28)\end{array}$

* Modulatory effect also seen in this area with the placebo group 


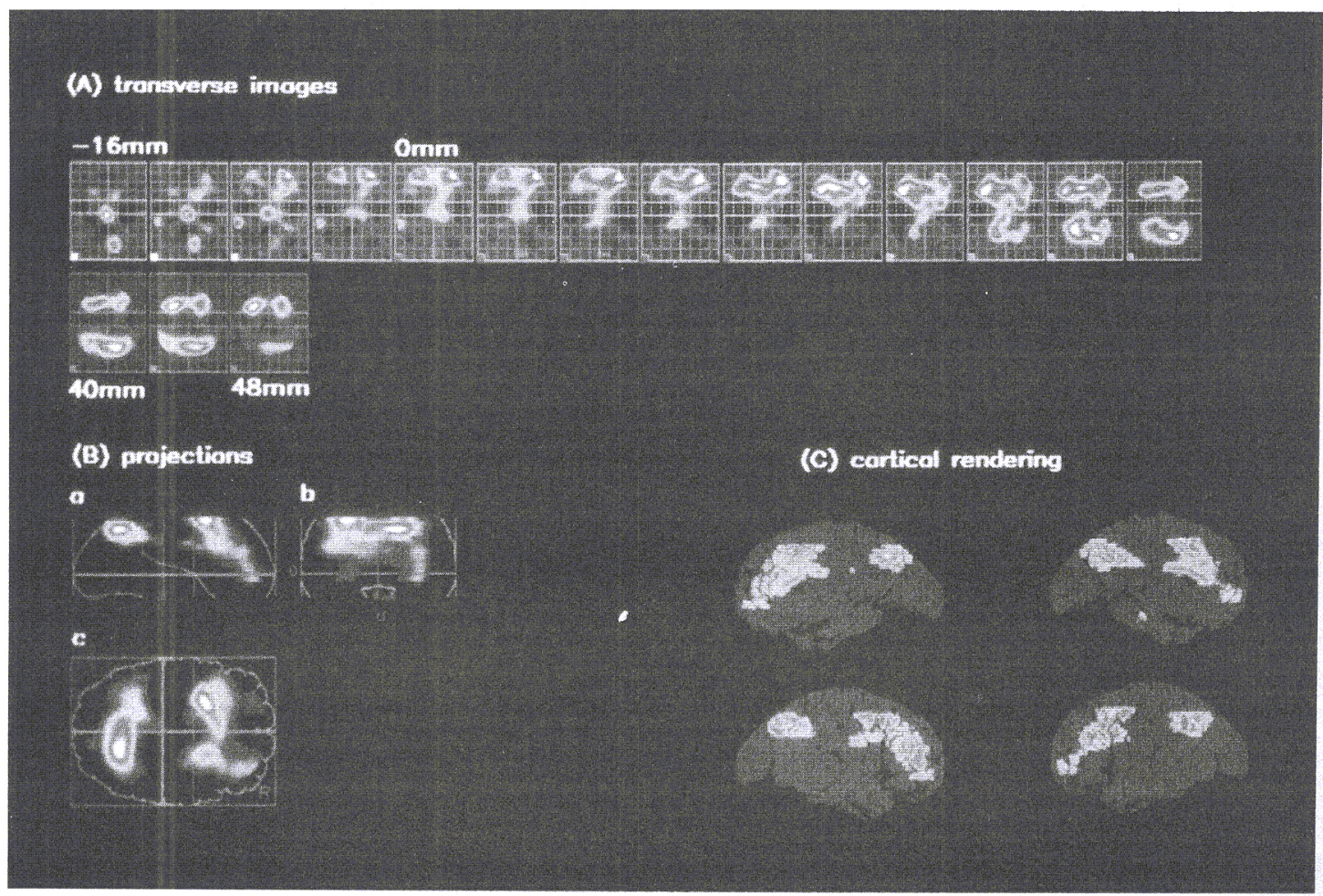

\section{Discussion}

In this study, scopolamine administration had regionally selective effects on an index of relative rCBF. Scopolamine increased $\mathrm{rCBF}$ in the lateral occipital cortex and the left orbitofrontal region and decreased $\mathrm{rCBF}$ in the region of the right thalamus, the precuneus and the right and left premotor areas. In addition, however, this study showed that scopolamine acted also in other areas of the brain, specifically modulating rCBF activations due to a supraspan memory task.

Scopolamine-induced increases/decreases of $\mathrm{rCBF}$ - correspondence with previous studies

The sites of scopolamine-induced changes of $\mathrm{rCBF}$ in this study show some similarities with the changes in regional cerebral glucose consumption following scopolamine administration $\left(0.25 \mathrm{mg} / \mathrm{m}^{2}\right.$ i.v. $)$ in normal volunteers (Blin et al. 1994). In the study by Blin and colleagues, increases of absolute glucose consumption were noted in nearly all brain regions studied using a region of interest analysis, with a global increase of glucose consumption of $14 \%$. The greatest increases in glucose consumption $(20-21 \%)$ were in the occipital, parietal association and hippocampal regions, whilst the thalamus showed the smallest change (increase 5\%). In our study, using an index of rCBF that was normalized to global flow, relative increases of $\mathrm{rCBF}$ were also located in the occipital region and relative decreases were noted in the thalamus. However, we did not detect relative increases of $\mathrm{rCBF}$ in hippocampal and parietal association cortex
Fig. 4A-C Supraspan-induced increases of $\mathrm{rCBF}$ in the placebo group. A Tranverse images in the stereotactic space of Talairach and Tournoux (1988) showing areas of significant increase of rCBF with the supraspan memory task. Numbers refer to millimetres above or below the anterior-posterior commissure line. The coloured square at the bottom left of an image represents a signifi. cance of $P<0.001$ for supraspan-induced increases of rCBF. B The spatial distribution of significant pixels at $P<0.001$ for suprasparinduced increases of $\mathrm{rCBF}$. Images are shown as integrated projections through sagittal $(a)$, coronal $(b)$ and tranverse $(c)$ views of the brain ( $R$ right). C For illustrative purposes only, significant pixels at $P<0.001$ have been rendered onto lateral and medial views of the left and right hemisphere taken from the Talairach and Tournoux atlas

regions. Such discrepancies are not altogether surprising given the different doses, routes and time of drug admin istration, and possibly imaging methods and data analy. sis techniques.

We are aware of one other study reporting $\mathrm{rCBF}$ changes following scopolamine administration in normal volunteers. Honer et al. (1988) measured rCBF using the xenon inhalation technique. Following scopolamine $7.3 \mu \mathrm{g} / \mathrm{kg}$ i.v., global reductions in $\mathrm{CBF}$ were noted after $25 \mathrm{~min}$, the greatest reductions being in the frontal is gions. The highest per cent reduction in $\mathrm{rCBF}(-22 \%)$ was reported over the superior posterior frontal areas. This area is in a similar location to the reductions of $\mathrm{rCBF}$ (normalized to global flow), localized to the premotor regions, in our study. The smallest reductions of rCBF in Honer's study were reported for the occipitat cortex $(-11 \%)$, where we detected the greatest increase in relative $\mathrm{rCBF}$, normalized to global flow. Thus this study, using a different imaging method, shows a degree of correspondence with our results. Furthermore, our re- 


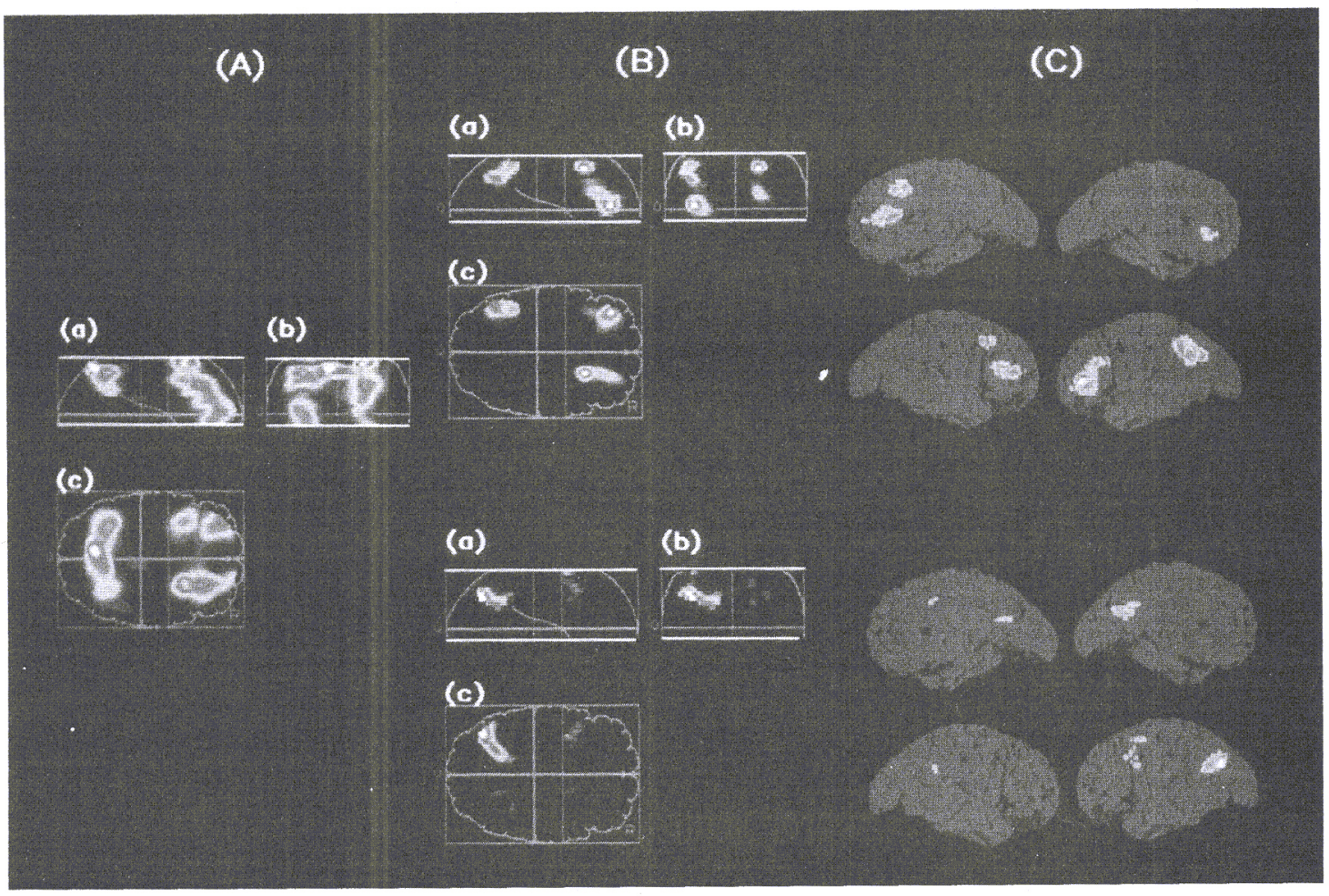

ts mirror the opposite effects seen with the anticholinerase inhibitor physostigmine. In rats, physostigmine reases glucose metabolism in the anterior thalamus 1 decreases metabolism in the occipital and parietal tex (Ray et al. 1992; Blin et al. 1994). A trend for inased thalamic metabolism has also been reported folving physostigmine administration in Alzheimer's pants (Blin et al. 1994). Taken together, these results wld suggest that functional activity (indexed by rCBF glucose metabolism) in the occipital cortex and thalais are particularly sensitive to the effects of manipulans of cholinergic neurotransmission in man.

larmacological mechanism

scopolamine-induced changes in $\mathrm{rCBF}$

ther of two mechanisms might account for the obaved effects of scopolamine on rCBF; a direct effect of opolamine on cerebral blood vessels or an effect of opolamine on neuronal firing, with consequent changin glucose metabolism and $\mathrm{rCBF}$. Evidence for a diteffect on cerebral vessels would be the fact that the erebral vasculature contains cholinergic fibres and musarinic receptors and that acetylcholine is vaso-active Burnstock 1980; Edvinsson et al. 1993). If a direct efct of scopolamine on the cerebral vasculature had ocirred in this experiment, a change of global CBF might ave been expected. Although we did not measure absothe $\mathrm{rCBF}$ in this study (arterial cannulation was not perbrmed), we did not detect any changes in the global raloactivity counts for subjects across scans $(P<0.05$, NOVA, $F=1.04$, df 5, 30). More convincingly, highly
Fig. 5 Supraspan-memory-induced increases of rCBF and attenuations with scopolamine/placebo. A Volume images in the stereotactic space of Talairach and Tournoux (1988) showing areas of significant increase of rCBF with the supraspan-subspan comparison in scopolamine-treated subjects at $P<0.001$. Images are shown as integrated projections through sagittal $(a)$, coronal $(b)$ and transverse $(c)$ views of the brain ( $R$ right). B Volume images in the stereotactic space of Talairach and Tournoux showing areas of scopolamine-induced (upper set) or placebo-induced (lower set) attenuation of rCBF increases in the supraspan-subspan comparison in $\mathbf{A}$ at $P<0.05$. C Scopolamine-induced (upper set) or placebo-induced (lower set) attenuation of $\mathrm{rCBF}$ increases in the supraspan - subspan comparison in $\mathbf{A}$ at $P<0.05$. For illustrative purposes only significant pixels have been rendered onto medial and lateral views of the left and right hemisphere taken from the Talairach and Tournoux atlas

regionally selective effects of scopolamine on $\mathrm{rCBF}$ were observed and included both increases and decreases of $\mathrm{rCBF}$ and modulation of neurogenic (psychological task) induced rCBF changes. It would appear unlikely that such changes were the direct effect of regionally selective vasodilation and vasoconstriction of cerebral blood vessels.

Scopolamine's antagonist action at muscarinic receptors results in the blockade of presynaptic and postsynaptic muscarinic receptors (Bymaster et al. 1993). Acting at the presynaptic autoreceptor on the cholinergic neuron, scopolamine enhances acetylcholine release; however, overall muscarinic cholinergic neurotransmission is likely to be blocked due to antagonism at the postsynaptic muscarinic receptor. The $\mathrm{rCBF}$ changes noted in this study may therefore reflect the overall functional effects of blockade of cholinergic (muscarinic) neurotransmission. However, this may be a oversimplification because 
(A)

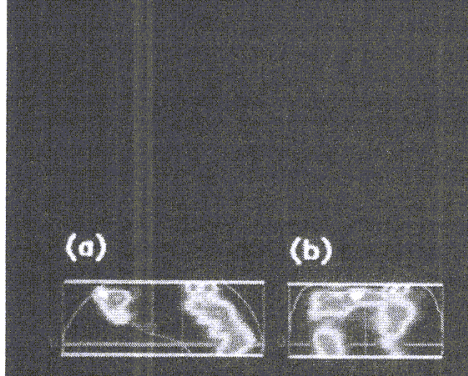

(c)

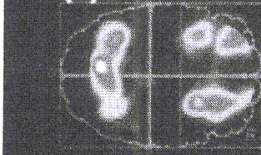

(B)

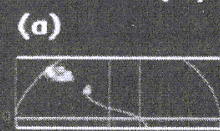

(c)

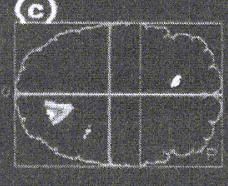

(o)

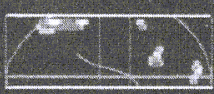

(b)

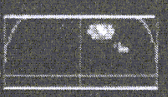

(c)

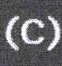

(c) (b)

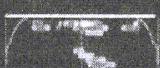

(1)
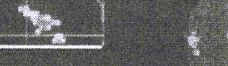

(4)
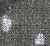
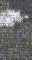

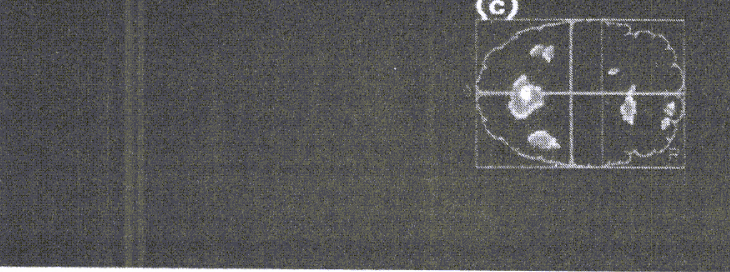

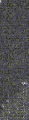
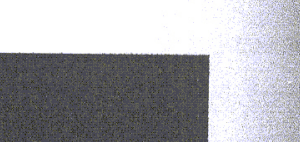

(1) increased presynaptic release of acetylcholine may result in enhanced nicotinic neurotransmission, (2) muscarinic antagonists may increase dopamine release (Dewey et al. 1993), (3) drug effects in vivo may reflect actions on integrated neuronal circuits involving multiple neurotransmitters (see McCulloch 1982).

Functional considerations of cholinergic modulation of occipital, thalamic and premotor $\mathrm{rCBF}$

The spatially restricted focus of $\mathrm{rCBF}$ activation in the lateral occipital cortex was unexpected. The use of smoothing filters at the stage of data analysis means that the reported $\mathrm{rCBF}$ values in the pixel of maximum $\mathrm{rCBF}$ change represent blood flow in a weighted spherical domain of about $20 \mathrm{~mm}$ diameter. Given the bilateral nature of the activations, this would suggest that the area of maximal rCBF change is located in the lateral rather than medial aspect of the occipital cortex. Furthermore, visual stimulation experiments using the imaging methods and data analysis described above allow a clear separation of medial and lateral occipital activations (Watson et al. 1993). These foci of activation are in the region of the recently described human visual motion area V5 of the lateral occipital cortex, although the mean spatial co-ordinates for V5 are slightly more lateral to the foci of maximal change induced by scopolamine [left: V $5-44$, -70 , 0 vs $-32,-78,0$; right: V5 $+40,-68,0$ vs $+20,-80$, 12 ; co-ordinates in $x, y$ and $z$ planes, respectively (Watson et al. 1993)]. The occipital changes might relate to the reported transient impairment of ocular accommodation, including blurred vision and mydriasis, that occurs

Fig. 6 Memory-induced increases of $\mathrm{rCBF}$ and augmentations with scopolamine/placebo. A Volume images in the stereotactic space of Talairach and Tournoux (1988) showing areas of signifi cant increase of $\mathrm{rCBF}$ with the supraspan-subspan comparison in scopolamine-treated subjects at $P<0.001$. Images are shown as in tegrated projections through sagittal $(a)$, coronal $(b)$ and transverse (c) views of the brain ( $R$ right). B Volume images in the stereotac tic space of Talairach and Tournoux showing areas of scopol amine-induced (upper set) or placebo-induced (lower set) allg mentation of $\mathrm{rCBF}$ increases in the supraspan-subspan comparison in $\mathbf{A}$ at $P<0.05$. C Scopolamine-induced (upper set) or placebo-induced (lower set) augmentation of $\mathrm{rCBF}$ increases in the suprit span-subspan comparison in A. For illustrative purposes only sige nificant pixels have been rendered onto medial and lateral views of the left and right hemisphere taken from the Talairach and Tor: noux atlas

with scopolamine. However, the subjects' eyes were closed throughout scanning, making this explanation unlikely. Given the anatomical specificity of the $\mathrm{rCB}$ changes in the occipital cortex, we would predict that scopolamine may have distinct effects on aspects of visual processing. In this regard, it is interesting that scopolamine prolongs the latency of the $\mathrm{P} 2$ and $\mathrm{N} 3$ components of flash-induced visual evoked responses (Bajalan et al. 1986); also, anticholinergics induce a state of dreamless sleep (Heller-Brown 1990) and, in high doses, cause vi. sual hallucinations (Crowell and Ketchum 1967; Ketchum et al. 1973). In addition, during REM sleep, when cholinergic neurotransmission is assumed to be operative (Steriade and McCarley 1990), glucose metabolism is increased in the lateral occipital areas (Maquet et al. 1990).

The thalamus has a key role in the control and regula. tion of cortical activity in both primates and man, with thalamocortical oscillations being postulated to determine states of sleep and arousal (Steriade et al. 1993). 
7 Scopolamine-induced enuations of supraspan $\mathrm{rCBF}$ meases. Numbers on the $x$ is refer to the pre-scopolmine (I) and two post-scopolmine $(2,3)$ supraspan-subspan mparisons. Values on the axis refer to $\mathrm{rCBF}$ change for esupraspan-subspan compar60. Number in parentheses wer to $x, y, z$ coordinates (alairach and Tournoux 1988)

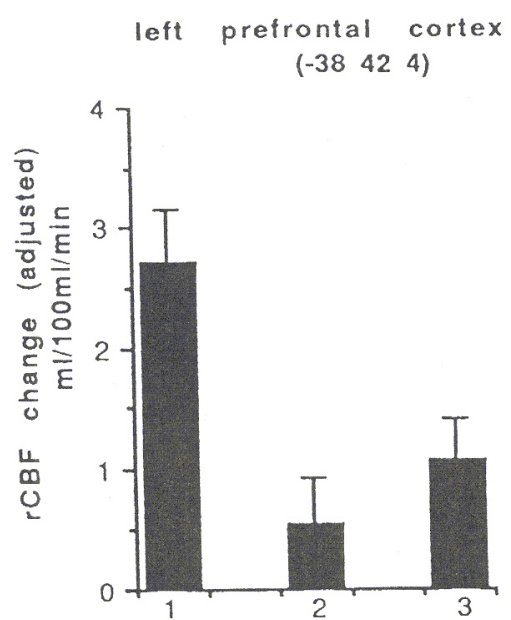

right prefrontal/cingulate cortex (20 30 16)

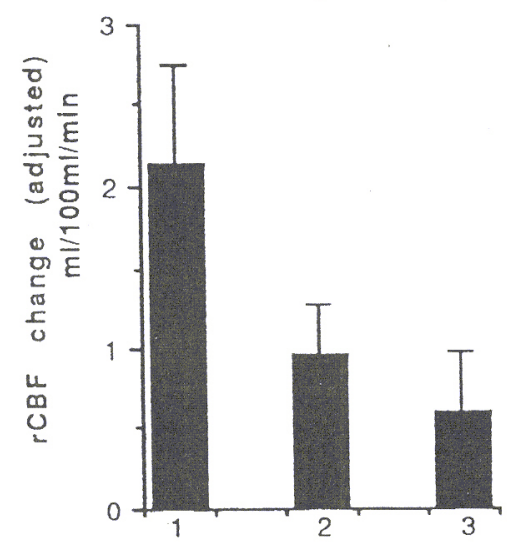

left prefrontal cortex $\left(\begin{array}{lll}-38 & 24 & 28\end{array}\right)$
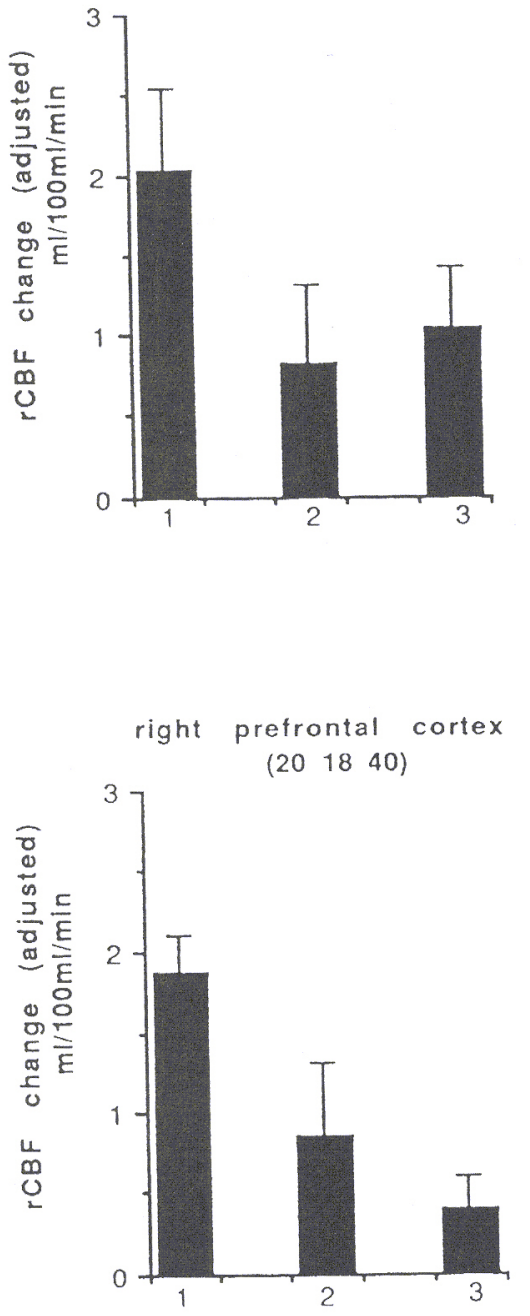

rain stem cholinergic systems are important for the ontrol of neuronal excitability during the sleep/wake cyte, and brain stem cholinergic neurones directly excite halamocortical neurones (Steriade and McCarley 1990). lodulation of thalamic function might therefore have aused the observed changes of cortical activity in this tudy, although more widespread alterations might have seen expected as bilateral thalamic infarction results in idespread reductions in cortical glucose metabolism Baron et al. 1986).

Blood flow in the lateral premotor area was reduced scopolamine administration. The lateral premotor reas are implicated in movement control, particularly the planning and selection of movement (Passingham 993). Anticholinergics, such as scopolamine, have iild antiparkinsonian effects and can be used in the reatment of tremor and dystonia (Lang 1989; Cedaraum and Schleifer 1990). Although anticholinergics nay act in Parkinson's disease and other movement disrders at the level of the basal ganglia (Calne 1978; eigh 1989; Kemel et al. 1992), the results presented ere would suggest that the lateral premotor areas might be considered a site at which some of the clinical effects of anticholinergics on motor symptoms might be mediated.

Scopolamine-induced modulation of supraspan increases of $\mathrm{rCBF}$

The main effect of scopolamine on rCBF, as described above, was to change rCBF in select brain areas such as the lateral occipital cortex, thalamus and premotor areas. These main effects occurred under both the subspan and supraspan conditions. Whilst any of these sites might be a potential candidate region for the amnesic effect of scopolamine, the most direct evidence for the location of scopolamine's amensic effect was obtained by the anatomical distribution of scopolamine/memory interactions.

The increases of $\mathrm{rCBF}$ in the supraspan condition in the placebo scans were as reported previously and illustrate that a network of anatomically distant areas are associated with supraspan memory activation (Grasby et 
al. 1993). A similar set of regions was activated in the scopolamine group by the supraspan task (compare Figs. 4 and 5). We chose the scopolamine supraspan activations, defined by a subset of pixels in stereotactic space, to examine the pattern of modulatory effects of scopolamine on memory-related rCBF increases. Within the network of regions so identified, scopolamine was found to have modulatory (attenuating) effects in the left and right prefrontal cortex, the right anterior cingulate region and the left inferior lateral parietal area and augmenting effects in the precuneus (Figs. 5, 6). When these same areas were examined in the placebo condition, only the left inferior lateral parietal and precuneus showed similar modulations (Table 3, Figs. 5, 6). Thus, scopolamine appears to selectively modulate left and right prefrontal/right anterior cingulate memory activations (Fig. 7). These attenuating effects were also noted when making a quantitative comparison between the scopolamine and placebo groups (data not shown), although the attenuation focus in the left prefrontal cortex reached significance in a few pixels only. These attenuating effects may represent the direct neural correlate of scopolamine's amnesic effect.

The exact role of prefrontal areas in mnemonic function remains a matter of continuing debate; thus, while many aspects of mnemonic function remain intact in patients with prefrontal lesions, other subtle aspects of memory function, such as judgements of item recency, temporal order and the use of mnemonic strategies, may be impaired (see Shimamura et al. 1991). Recent memory activation studies using PET suggest that the left and right prefrontal cortex have distinct roles in episodic memory function with the left prefrontal cortex being involved in the processes of encoding and or the organization of material to be remembered, while the right prefrontal cortex may be involved in the retrieval and or verification of episodic memories (Shallice et al. 1994; Tulving et al. 1994). The data in this paper would suggest that scopolamine's amensic effect might be mediated via an action on those memory processes subserved by the left and right prefrontal cortices.

A further possible site of scopolamine's amnesic ef fects is the right anterior cingulate as attenuations of supraspan rCBF increases occurred in this region (Fig. 5) The right anterior cingulate has been most clearly implicated in attentional tasks (Pardo et al. 1990; Bench et al. 1993). Scopolamine is reported to impair performance on attentional type tasks such as simple and choice reaction time, digit checking, vigilance and sustained rapid visual information processing (see Rusted 1994). The attenuation of $\mathrm{rCBF}$ responses in this region would therefore suggest that one effect of scopolamine on memory function is in part mediated through an action on attentional mechanisms that involve the anterior cingulate cortex.

We did not detect a cholinergic or memory task mod ulation of hippocampal rCBF in this experiment. This is surprising given the strong cholinergic projections from the basal forebrain to this structure (McGeer et al. 1987) and the postulated role of the hippocampus in memory function (Squire and Zola-Morgan 1991). However, there is an often documented mismatch between the regional receptor/terminal innervation density of neuronal systems sensitive to a drug and drug effects on rCBF (see McCulloch 1982). Furthermore, the theoretical "sparseness" of hippocampal neuronal activation during memory encoding (Rolls and Treves 1990) may explain the failure to detect hippocampal $\mathrm{rCBF}$ change during the memory task. Alternatively, or additionally, the memory tasks chosen (subspan and supraspan) may not be sufficiently sensitive to produce a differential activation of the hippocampus in the supraspan task.

Altogether, scopolamine attenuated memory activations in a small number of functionally distinct brain areas. It appears, therefore, that cholinergic neurotransmission modulates a memory network at more than one point. As each point of this memory network is unlikely to be equipotential, in terms of the memory processes subserved (Shallice et al. 1994), it is possible that scopolamine acts to influence a number of discrete functions, including organizational, verification and attentional mechanisms, that are operative together during memory processing.

\section{References}

Bailey DL, Jones T, Friston KJ, Colebatch JG, Frackowiak RS. (1991) Physical validation of statistical parametric mapping. I Cereb Blood Flow Metab 11 [suppl 2]: S150

Bajalan AAA, Wright CE, Van Der Vleit VJ (1986) Changes in the human visual evoked potential caused by the anticholinergic agent hyoscine hydrobromide: comparison with results from Alzheimer's disease. J Neurol Neurosurg Psychiatry 49: $175-182$

Baron JC, D'Antona R, Pantano P, Serder M, Samson Y, Bousser MG (1986) Effects of thalamic stroke on energy metabolism of the cerebral cortex. Brain 109: 1243-1259

Bench CJ, Frith CD, Grasby PM, Friston KJ, Paulesu E. Frackowiak RSJ, Dolan RJ (1993) Investigations of the fune tional anatomy of attention using the stroop test. Neuropsychologia 31: 907-922

Blin J, Ray CA, Piercey MF, Bartko JJ, Mouradian MM, Chase TN (1994) Comparison of cholinergic drug effects on regionai brain glucose consumption in rats and humans by means of all toradiography and positron emission tromography. Brain Re 635: $196-202$

Burnstock G (1980) Cholinergic and purinergic regulation blood vessels. In: Bohr DF, Somolyo AP, Sparks HV (eds Handbook of physiology, sect 2, The cardiovascular system vol 2. American Physiological Society, Bethesda, pp 567-612

Bymaster FP, Heath I, Hendrix JC, Shannon HE (1993) Comparative behavioural and neurochemical activities of cholinergi antagonists in rats. J Pharmacol Exp Ther 267: 16-24

Calne DB (1978) Parkinsonism, clinical and neuropharmacologic aspects. Postgrad Med 64: 82-88

Cedarbaum JM, Schleifer LS (1990) Drugs for Parkinson's disease, spasticity and acute muscle spasms. In: Goodman Gil man A, Rall TW, Nies AS, Taylor P (eds) Goodman and Gil man's The pharmacologic basis of therapeutics. Pergamon Press, New York, pp 463-484

Collerton D (1987) Problems in the cognitive neurochemistry of Alzheimer's disease. In: Stahl SM, Iversen SD, Goodman EC (eds) Cognitive neurochemistry. Oxford University Press, 0xford, pp 272-302 
TJ, Grove-White IG (1973) An analysis of the learning defit following hyoscine administration to man. Br J Pharmacol ): $322-327$

all EB, Ketchum JS (1967) The treatment of scopolamine-iniced delirium with physostigmine. Clin Pharmacol Ther 8: $99-414$

y SL, Smith GS, Logan J, Bridie JD, Simkowitz P, MacGr,or RR, Fowler JS, Volkow ND, Wolf AP (1993) Effects of intral cholinergic blockade on striatal dopamine release meaired with positron emission tomography in normal human bjects. Proc Natl Acad Sci USA 90: 11816-11820

iman DA, Leavitt J (1974) Human memory and the cholineric system. Arch Neurol 30: 113-121

isson L, MacKenzie ET, McCulloch J (1993) Acetylcholine. 1: Edvinsson L, MacKenzie ET, McCulloch J (eds) Cerebral lood flow and metabolism. Raven Press, New York, pp $85-312$

PT, Mintun MA (1989) Non-invasive functional brain maping by change distribution analysis of averaged PET images $\mathrm{fH}_{2} 15 \mathrm{O}$ tissue activity. J Nucl Med 30: 141-149

in KJ, Passingham RE, Nutt JG, Heather JD, Sawle GV, rackowiak RSJ (1989) Localization in PET images: direct fitng of the intercommissural (AC-PC) line. J Cereb Blood low Metab 9: 690-695

on KJ, Frith CD, Liddle PF, Lammertsma AA, Dolan RJ, irackowiak RSJ (1990) The relationship between local and lobal changes in PET scans. J Cereb Blood Flow Metab 10: $58-466$

on KJ, Frith CD, Liddle PF, Frackowiak RSJ (1991a) Plastic ansformation of PET images. J Comput Assist Tomogr 15: i34-639

on KJ, Frith CD, Liddle PF, Frackowiak RSJ (1991b) Comraring functional (PET) images: the assessment of significant hange. J Cereb Blood Flow Metab 11: 690-699

on KJ, Grasby PM, Bench C, Frith CD, Cowen PJ, Liddle PF, irackowiak RSJ, Dolan RJ (1992) Measuring the neuromoduatory effects of drugs in man with positron emission tomograhy. Neurosci Lett 141: 106-110

by PM. Friston KJ, Bench CJ, Frith CD, Paulesu E, Cowen J, Liddle PF, Frackowiak RSJ, Dolan RJ (1992) The effect of tpomorphine and buspirone on regional cerebral blood flow luring the performance of a cognitive task - measuring neuronodulatory effects of psychotropic drugs in man. Eur $J$ Neuroici 4: $1203-1212$

by PM, Frith CD, Friston KJ, Bench C, Frackowiak RSJ, Doan RJ (1993) Functional mapping of brain areas implicated in uditory-verbal memory function. Brain 116: 1-20

d DJ, Taylor CC (1991) Multivariate analysis of variance and epeated measures. Chapman and Hall, London, pp 9-44

er-Brown J (1990) Atropine, scopolamine and related antimuscarinic drugs. In: Goodman Gilman A, Rall TW, Nies AS, Taylor P (eds) Goodman and Gilmans The pharmacologic basis of therapeutics. Pergamon Press, New York, pp 150-165 er WG, Prohovnik I, Smith G, Lucas LR (1988) Scopolamine reduces frontal cortex perfusion. J Cereb Blood Flow Metabol 8: 635-641

el ML, Desban M, Glowinski J, Gauchy C (1992) Functional heterogenity of the matrix compartment in the cat caudate nucleus as demonstrated by the cholinergic presynaptic regulation of dopamine release. Neuroscience 50: 597-610

zhum JS, Sidell FR, Crowell EB, Aghajanian GK, Haines AH (1973) Atropine, scopolamine and ditran: comparative pharmacology and antagonists in man. Psychopharmacologia 28: $121-145$

velman MD (1987) How far could cholinergic depletion account for the memory deficits of Alzheimer-type dementia or the alcoholic Korsakoff syndrome. In: Stahl SM, Iversen SD, Goodman EC (eds) Cognitive neurochemistry. Oxford University Press, Oxford, pp 303-326

nmertsma AA, Cunningham VJ, Deiber MP, Heather JD, Bloomfield PM, Nutt JG, Frackowiak RSJ, Jones T (1990) Combination of dynamic and integral methods for generating reproducible functional CBF images. J Cereb Blood Flow Metabol 10: 675-686

Lang AE (1989) Drug treatment of dystonia. In: Quinn NP, Jenner PG (eds) Disorders of movement: clinical, pharmacological and physiological aspects. Academic Press, London, pp 315317

Leigh PN (1989) Functional organization of the basal ganglia. In: Quinn NP, Jenner PG (eds) Disorders of movement: clinical, pharmacological and physiological aspects. Academic Press, London, pp 18-19

Mackay C, Cox T, Burrows G, Lazzerini T (1978) An inventory for the measurement of self-reported stress and arousal. $\mathrm{Br} \mathrm{J}$ Soc Clin Psychol 17: 283-284

Maquet P, Dive D, Salmon E, Sadzot B, Franco G, Poirrier R, von Frenckell R, Franck G (1990) Cerebral glucose utilization during sleep-wake cycle in man determined by positron emission tomography and $\left[{ }^{18} \mathrm{~F}\right] 2$-fluro-2-deoxy-D-glucose method. Brain Res 513: 136-143

Mazziotta JC, Huang SC, Phelps ME, Carson RE, MacDonalds NS, Mahoney K (1985) A non-invasive positron computed tomography technique using oxygen-15 labelled water for the evaluation of neurobehavioural task batteries. J Cereb Blood Flow Metab 5: 70-78

McCulloch J (1982) Mapping functional alterations in the CNS with $\left[{ }^{14} \mathrm{C}\right]$-deoxyglucose. In: Iversen LI, Iversen SD, Snyder SH (eds) Handbook of psychopharmacology. Plenum, New York, pp 321-410

McGeer PL, Eccles JC, McGeer EG (1987) Cholinergic Neurons. In: McGeer PL, Eccles JC, McGeer EG (eds) Molecular neurobiology of the mammalian brain. Plenum, New York, pp 237-263

Pardo JV, Pardo PJ, Janer KW, Raichle ME (1990) The anterior cingulate cortex mediates processing selection in the stroop attentional conflict paradigm. Proc Natl Acad Sci USA 87: 256-259

Passingham R (1993) The frontal lobes and voluntary action. Oxford University Press, Oxford, pp 38-68

Posner MI, Petersen SE, Fox PT, Raichle ME (1988) Localization of cognitive operations in the human brain. Science 240: $1627-1631$

Quinlan P T (1992) The Oxford psycholinguistic database. Oxford University Press, Oxford

Raichle ME (1987) Circulatory and metabolic correlations of brain function in normal humans. In: Plum F (ed) Handbook of physiology, sect 1 . The nervous system, vol 5: higher functions of the brain. Oxford University Press, New York, pp 643-674

Ramsay SC, Murphy K, Shea SA, Friston KJ, Lammertsma AA, Clark JC, Adams L, Guz A. Frackowiak RSJ (1993) Changes in global cerebral blood flow in humans: effect on regional cerebral blood flow during a neural activation task. J Physiol (Lond) 471: 521-534

Ray CA, Blin J, Chase TN, Piercey MF (1992) Effects of cholinergic agonists on regional brain energy metabolism in the scopolamine-treated rat. Neuropharmacology 31: 1193-1199

Robb RA (1990) A software system for interactive and quantitative analysis of biomedical images. In: Hohne KH, Fuchs $\mathrm{H}$, Pizer SM (eds) 3D Imaging in Medicine. NATO ASI Series, Springer, London

Rolls ET, Treves A (1990) The relative advantage of sparse versus distributed encoding for associative neuronal networks in the brain. Network 1: 407-421

Rusted J (1994) Cholinergic blockade and human information processing: are we asking the right questions? J Psychopharmacol 8: 54-59

Sahakian BJ (1988) Cholinergic drugs and human cognitive performance. In: Iversen LI, Iversen SD, Snyder SH (eds) Handbook of psychopharmacology. Plenum, New York, pp 393424

Shallice T, Fletcher P, Frith CD, Grasby P, Frackowiak RSJ, Dolan RJ (1994) The brain regions associated with the acquisition and retrieval of verbal episodic memory. Nature 368: 633-635 
Shimamura AP, Janowsky JS, Squire LR (1991) What is the iole of frontal lobe damage in memory disorders? In: Levin HS, Eisenberg HM, Benton AL (eds) Frontal lobe function and dysfunction. Oxford University Press, New York, pp 173-195

Soncrant TT, Pizzolato G, Battistin L (1986) The use of drugs as probes of cerebral function. In: Battistin L, Gerstenbrand $\mathrm{F}$ (eds) PET and NMR: new perspectives in neuroimaging and in clinical neurochemistry. Liss, New York, pp 131-149

Spinks TJ, Jones T, Gilardi MC, Heather, JD (1988) Physical performance of the latest generation of commercial positron scanner. IEEE Trans Nucl Sci 35: 721--725

Squire LR, Zola-Morgan S (1991) The medial temporal lobe memory system. Science 253: 1380-1386

Steriade M, McCarley RW (1990) Brainstem control of wakefulness and sleep. Plenum Press, New York, pp 164-185

Steriade M, McCormick DA, Sejnowski TJ (1993) Thalamocortical oscillations in the sleeping and aroused brain. Science 262 : $679-685$
Talairach J, Tournoux P (1988) A co-planar stereotactic atlas of human brain. Thieme, Stuttgart

Tulving E, Kapur S, Craik FIM, Moscovitch M, Houle S (1994) Hemispheric encoding/retrieval asymmetry in episodic memory: positron emission tomography findings. Proc Natl Acad Sci USA 91: 2016-2020

Watson JDG, Myers R, Frackowiak RSJ, Hajnal JV, Woods RP, Mazziotta JC, Shipp S, Zeki S (1993) Area V5 of the human brain: evidence from a combined study using positron emis sion tomography and magnetic resonance imaging. Cereb Cortex 3: 79-94

Wildt AR, Ahtola OT (1978) Analysis of covariance. (University papers: Quantitative applications in the social sciences ser no. 12). Sage Publications, Beverly Hills, California

Woods RP, Cherry SR, Mazziotta JC (1992) A rapid automated al. gorithm for accurately aligning and reslicing positron emission tomography images. J Comput Assist Tomogr 16: 620-633 